\title{
Butadiene-Functionalized Poly(dimethylsiloxane) Macromonomer
}

\author{
Yusuke Kawakami, ${ }^{\dagger}$ Kaori Ajima, Makoto Nomura, Tatsuhiro Hishida, \\ and Atsunori MorI
}

Graduate School of Materials Science, Japan Advanced Institute of Science \& Technology, Asahidai 1-1, Tatsunokuchi, Ishikawa 923-12, Japan

(Received June 17, 1996)

\begin{abstract}
KEY WORDS Cyclic Siloxane / Butadienyllithium / Hexynyllithium / Ring-Opening / Silanolate / Initiation / Living Polymerization / Macromonomer / Precision Synthesis /
\end{abstract}

Poly(dimethylsiloxane)s possess flexible molecular structures and exhibit considerably different and unique properties, for instance low glass transition temperature, from common organic polymers. ${ }^{1}$ Therefore, it is of great interest to design copolymers composed of common organic polymers and poly(dimethylsiloxane) (PDMS) to develop unique properties of the resulting copolymers. Graft copolymer is one of the candidates of such copolymers, whose properties very much depend on the chemical and microphase-separated structure. Macromonomer method is a unique method to synthesize well-defined graft copolymers. ${ }^{2}$ To design well-defined graft copolymers with definite branch structures, it is quite important to precisely synthesize macromonomers of definite and wide range of degree of polymerization. Macromonomers of PDMS have been mainly synthesized by the introduction of a polymerizable functional group by termination reaction of $n$-butyllithium (BuLi) initiated polymerization of hexamethylcyclotrisiloxane $\left(\mathrm{D}_{3}\right)$ with a silyl chloride bearing a polymerizable functional group. ${ }^{3}$ It seems also possible that the functional group is introduced by the initiation reaction by an organolithium compound with a polymerizable functional group.

We recently described a facile synthesis of functionalized disiloxanes by alkylative cleavage of $D_{3}$ followed by end-capping with a chlorosilane ${ }^{4}$ as shown in eq 1 in Scheme 1. We also reported a synthesis of functionalized disiloxane by reactions of methyllithium and function- alized cyclic siloxanes. ${ }^{5}$ During the study, a variety of functional alkyllithiums was found to give the lithium silanolate composed of one or three $\mathrm{Si}-\mathrm{O}$ units by controlling the stoichiometry of the reagents. Such macromonomers themselves not only have new chemical structures but also will give unique structures of graft copolymers and combine the unique properties of main chain and branches, for example, rubbery property of the main chain and surface activity of branches.

Further interest has been paid to the synthesis of a variety of the functionalized (with allyl, 2-(1,3- butadienyl), or hexynyl group) tetra- and polysiloxanes (macromonomer) by quenching the initially formed silanolate of trisiloxane or of polysiloxane by a chlorosilane. If the silanolate having three $\mathrm{Si}-\mathrm{O}$ units is treated with a chlorosilane, the corresponding tetrasiloxanes should be obtained (eq 2 in Scheme 1). When excess $D_{3}$ is used to the functionalized alkyllithium reagent, PDMS macromonomer with definite molecular weight and molecular weight distribution should be obtained if the polymerization proceeds in the living mode (eq 3 in Scheme 1).

\section{EXPERIMENTAL}

General

${ }^{1} \mathrm{H},{ }^{13} \mathrm{C}$, and ${ }^{119} \mathrm{Sn}$ NMR were measured in chloroform- $d$ using a Varian $300 \mathrm{MHz}$ NMR spectrometer, model Gemini 300 or $400 \mathrm{MHz}$ NMR model Unity 400 plus. The chemical shifts are expressed in ppm using

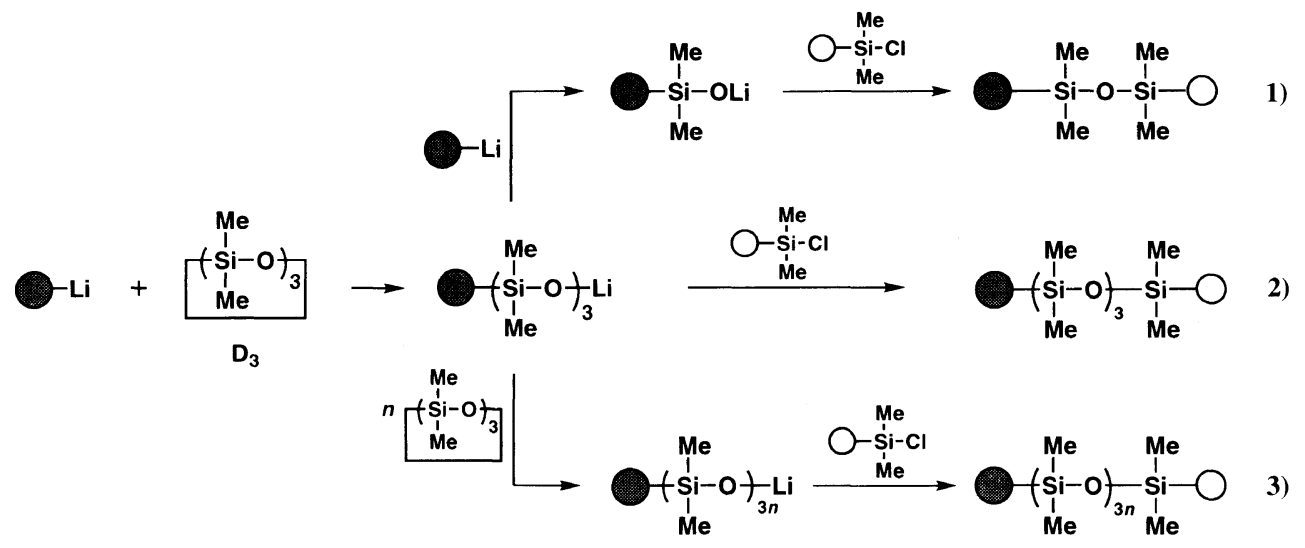

Scheme 1. Synthesis of di-, tetra-, and poly(dimethylsiloxane) with functional group.

\footnotetext{
* To whom correspondence should be addressed.
} 
chloroform $\left(\delta\right.$ 7.26) for ${ }^{1} \mathrm{H}$, chloroform- $d(\delta 77.1)$ for ${ }^{13} \mathrm{C}$, and tetrabutyltin $(\delta 0.00)$ for ${ }^{119} \mathrm{Sn}$ as internal standards, respectively. Gel permeation chromatography was performed on a JASCO high speed liquid chromatograph model 880 equipped with a differential refractometer and UV (254 $\mathrm{nm}$ and variable) detectors on Shodex columns KF-801 (exclusion limit, $M_{n}=1.5 \times 10^{3}$ for polystyrene) and KF-804 (exclusion limit, $M_{n}=4.0 \times$ $10^{5}$ for polystyrene) using tetrahydrofuran (THF) as an eluent (flow rate; $1.0 \mathrm{~mL} \mathrm{~min}^{-1}$ ) at $40^{\circ} \mathrm{C}$. The molecular weight and molecular weight distribution were estimated using standard polystyrene.

\section{Synthesis}

Organolithium Reagents. Allyllithium was synthesized by the reaction of tetraallyltin and phenyllithium in ether at $0^{\circ} \mathrm{C} .^{6} 1$-Hexynyllithium was synthesized according to standard methods for the synthesis of alkynyllithium ${ }^{7}$ from 1-hexyne and BuLi in ether or THF under nitrogen atmosphere. 2-(1,3-Butadienyl)lithium (BDLi) was synthesized from following the procedure reported by Tsuge. ${ }^{8,10}$ The extent of the reaction was checked by ${ }^{119} \mathrm{Sn}$ NMR. The resulting solution was directly used as the initiator solution after determination of the concentration of the lithium reagent.

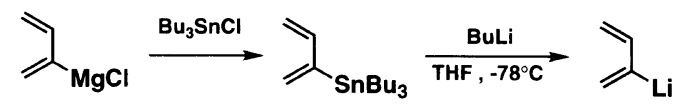

Scheme 2. Synthesis of 2-(1,3-butadienyl)lithium. ${ }^{8-10}$

Chlorosilanes. To determine the concentration of the living end, chlorosilanes with the UV-absorbing group, synthesized by hydrosilylation reaction of allyl derivatives in the presence of Pt-DVTMDS ${ }^{12}$ were used. The structures of the compounds are shown in Figure 1.

After the reaction was completed, excess dimethylchlorosilane was removed under reduced pressure and the resulting (3-substituted propyl)dimethylchlorosilane was directly used as the terminating agent.

3-(Biphenyl-4-yloxy)propyldimethylchlorosilane. White solid.

${ }^{1} \mathrm{H}$ Chemical shifts: $0.48\left(\mathrm{~s}, 6 \mathrm{H}, \mathrm{Si} M e_{2} \mathrm{Cl}\right), 1.00(\mathrm{~m}$,

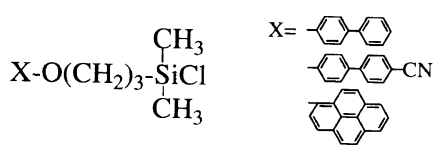

Figure 1. Chlorosilanes with UV-absorbing group. $\left.2 \mathrm{H}, \mathrm{CH}_{2} \mathrm{SiMe}_{2} \mathrm{Cl}\right), 1.95\left(\mathrm{~m}, 2 \mathrm{H}, \mathrm{OCH}_{2} \mathrm{CH}_{2}\right), 4.02(\mathrm{t}, 2 \mathrm{H}$, $\left.J=6.0, \mathrm{OCH}_{2}\right), 7.00(\mathrm{~d}, 2 \mathrm{H}, J=6.6 \mathrm{~Hz}, H w), 7.31(\mathrm{~m}$, $2 \mathrm{H}, H x), 7.41(\mathrm{~m}, 2 \mathrm{H}, H y), 7.54(\mathrm{~m}, 3 \mathrm{H}, \mathrm{Hz})$.

3-(4-Cyanobiphenyl-4'-yloxy)propyldimethylchlorosilane. White solid.

${ }^{1} \mathrm{H}$ Chemical shifts: $7.50(\mathrm{~d}, 2 \mathrm{H}, J=8.8 \mathrm{~Hz}, H x), 7.65$ (dd, $4 \mathrm{H}, J=8.8 \mathrm{~Hz}, \mathrm{Hy}, \mathrm{Hz}$ ).

Other protons appeared at similar positions with 3(biphenyl-4-yloxy)propyl-dimethlchlorosilane.

3-(Pyrenyl-1-yloxy)propyldimethylchlorosilane. Yellow liquid.

${ }^{1} \mathrm{H}$ Chemical shifts: $0.52\left(\mathrm{~s}, 6 \mathrm{H}, \mathrm{Si} \mathrm{Me}_{2} \mathrm{Cl}\right), 1.17(\mathrm{~m}$, $\left.2 \mathrm{H}, \mathrm{CH}_{2} \mathrm{SiMe}_{2} \mathrm{Cl}\right), 2.15\left(\mathrm{~m}, 2 \mathrm{H}, \mathrm{OCH}_{2} \mathrm{CH}_{2}\right), 4.33(\mathrm{t}, 2 \mathrm{H}$, $\left.J=6.0, \mathrm{OCH}_{2}\right), 7.56(\mathrm{~d}, 1 \mathrm{H}, J=8.52 \mathrm{~Hz}, \mathrm{Ha}), 8.00(\mathrm{~m}$, $7 \mathrm{H}, H b-H h), 8.51(\mathrm{~d}, 1 \mathrm{H}, J=9.12 \mathrm{~Hz}, H i)$.

Tetrasiloxane. Representative synthetic procedure of the functionalized tetrasiloxane is given for 7-allyl-1hydrooctamethyltetrasiloxane.

7-Allyl-1-hydrooctamethyltetrasiloxane. To an ethereal solution $(15 \mathrm{~mL})$ of allyllithium $(20 \mathrm{mmol})$ generated in situ, was added $\mathrm{D}_{3}(4.45 \mathrm{~g}, 20 \mathrm{mmol})$ in ether $(5 \mathrm{~mL})$ at $-78^{\circ} \mathrm{C}$ under nitrogen atmosphere. Stirring was continued for $2 \mathrm{~h}$ at $-78^{\circ} \mathrm{C}$ followed by at room temperature for $9 \mathrm{~h}$. Dimethylchlorosilane $(0.34 \mathrm{~g}, 20 \mathrm{mmol})$ was added, and the reaction mixture was stirred for $30 \mathrm{~min}$ at room temperature. The lithium chloride and tetraphenyltin precipitated were removed by filtration. Concentration and distillation of the residual oil gave 7allyl-1-hydrooctamethyltetrasiloxane as a colorless liquid (bp $52^{\circ} \mathrm{C} / 2 \mathrm{mmHg}$ ) in $59 \%$ yield.

${ }^{1} \mathrm{H}$ Chemical shifts: 0.06 (s, 6H, SiMe ${ }_{2} \mathrm{OSiMe}_{2} \mathrm{H}$ ), 0.07 (s, 6H, SiMe $\left.{ }_{2} \mathrm{OSiMe}_{2} \mathrm{OSiMe}_{2} \mathrm{H}\right), 0.10$ (s, 6H, $\mathrm{CH} 2 \mathrm{Si} M e_{2}$ ), 0.19 (d, 6H, $\left.J=2.8 \mathrm{~Hz}, \mathrm{Si}_{2} e_{2} \mathrm{H}\right), 1.58$ (d with fine coupling, $2 \mathrm{H}, J=7.5 \mathrm{~Hz}, \mathrm{CH}_{2} \mathrm{Si}$ ), 4.71 (hept, $1 \mathrm{H}, J=2.8 \mathrm{~Hz}, \mathrm{SiMe}_{2} H$ ), 4.85 (d with fine coupling, $1 \mathrm{H}, J=12.0 \mathrm{~Hz}, \stackrel{\mathrm{C}_{\mathrm{H}}}{=}<_{H}$ ), 4.87 (d with fine coupling, $1 \mathrm{H}$, $\left.J=12.0 \mathrm{~Hz},{\stackrel{\mathrm{H}}{\mathrm{CH}_{2}}}^{H}\right), 5.70-5.90\left(\mathrm{~m}, 1 \mathrm{H}, \mathrm{CH}_{2}=\mathrm{CH}\right) .{ }^{13} \mathrm{C}$ Chemical shifts: $134.37,113.30,26.26,1.106,0.861,0.691$, 0.305 .

The results of the synthesis of tetrasiloxane are summarized in Table I.

Macromonomers. To a solution of 2-(1,3-butadienyl) tributyltin (BDSn) $(0.34 \mathrm{~g}, 1.0 \mathrm{mmol})$ in THF $(2 \mathrm{~mL})$ was added a $1.6 \mathrm{M}$ hexane solution of BuLi $(0.61 \mathrm{~mL}$, $1.0 \mathrm{mmol}$ ) at $-78^{\circ} \mathrm{C}$ under argon atmosphere, and the reaction mixture was stirred for $1 \mathrm{~h}$. The solution im-

Table I. Synthesis of functionalized tetrasiloxanes

\begin{tabular}{|c|c|c|c|c|c|}
\hline $\mathrm{R}^{1}$ & $\mathrm{R}^{2}$ & Solvent & Product & Yield $/ \%$ & $\mathrm{Bp} /{ }^{\circ} \mathrm{C}(\mathrm{mmHg})$ \\
\hline$\leadsto$ & $\mathrm{H}$ & Ether & & 59 & $52(2)$ \\
\hline$\leadsto$ & $\mathrm{Ph}$ & Ether & & 77 & - \\
\hline $\mathrm{Bu}=$ & $\mathrm{Me}$ & THF & $=+\mathrm{Si}_{\mathrm{i}} \mathrm{O}+{ }_{3} \mathrm{Si}-$ & 79 & $50(2.5)$ \\
\hline$\lambda$ & $\mathrm{Me}$ & THF & & 67 & $81(3.0)$ \\
\hline
\end{tabular}

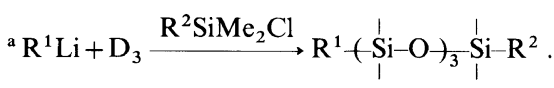


mediately turned reddish brown. To the resulting mixture was added $\mathrm{D}_{3}(2.23 \mathrm{~g}, 10 \mathrm{mmol})$ dissolved in THF $(10 \mathrm{~mL})$ at $-78^{\circ} \mathrm{C}$ and stirred for $3 \mathrm{~h}$ during which time the pinkish red color formed on the addition of $\mathrm{D}_{3}$ dissipated and became transparent. The reaction mixture was allowed to warm to room temperature. The reaction time was adjusted depending upon the monomer/ initiator ratio. After the polymerization was completed, trimethylchlorosilane (TMCS; $0.16 \mathrm{~g}, 1.5 \mathrm{mmol}$ ) was added at room temperature and stirring was continued for $1 \mathrm{~h}$. After excess TMCS and THF were removed under reduced pressure, the mixture was poured into saturated aqueous $\mathrm{NH}_{4} \mathrm{Cl}$, and the organic layer was separated. The aqueous layer was extracted with hexane $(50 \mathrm{~mL} \times 2)$, and the combined organic layer was dried over $\mathrm{MgSO}_{4}$ and concentrated in vacuo to leave a colorless slurry containing the formed polymer and tetrabutyltin. The tin compound was removed by washing with methanol. PDMS macromonomer was obtained as a colorless viscous oil.

${ }^{1} \mathrm{H}$ Chemical shifts: $0.04-0.10\left(\mathrm{~m},\left(\mathrm{SiMe}_{2} \mathrm{O}\right) \mathrm{SiMe}_{3}\right)$, $5.08\left(\mathrm{~d}, 1 \mathrm{H}, J=10.8 \mathrm{~Hz}, H_{4}\right), 5.34(\mathrm{~d}, 1 \mathrm{H}, J=17.7 \mathrm{~Hz}$, $\left.H_{5}\right), 5.52\left(\mathrm{~d}, 1 \mathrm{H}, J=3.3 \mathrm{~Hz}, H_{1}\right), 5.73(\mathrm{~d}, 1 \mathrm{H}, J=3.3 \mathrm{~Hz}$,

${ }^{13} \mathrm{C}$ Chemical shifts: $149.2,141.0,128.9,116.3$.

Polymerizations by methyllithium and hexynyllithium were carried out similarly.

\section{RESULTS AND DISCUSSION}

\section{Formation of 2-(1,3-Butadienyl)lithium}

When BDSn was mixed with BuLi at $-78^{\circ} \mathrm{C}$ in $\mathrm{THF}$, the solution turned reddish brown suggesting the formation of BDLi. Conversion of BDSn to BDLi was estimated by ${ }^{119} \mathrm{Sn}$ NMR and gas chromatography. Figure 2 a shows the ${ }^{119} \mathrm{Sn}$ NMR spectrum of the mixture of BDSn and tetrabutyltin $\left(\mathrm{Bu}_{4} \mathrm{Sn}\right)$ with broad band proton decoupling. The signal of BDSn appeared at $-31.1 \mathrm{ppm}$ higher field from $\mathrm{Bu}_{4} \mathrm{Sn}$.

The spectrum of the product is shown in Figure $2 \mathrm{~b}$ and indicated the complete disappearance of BDSn. Gas chromatographic analysis also confirmed the quantita-

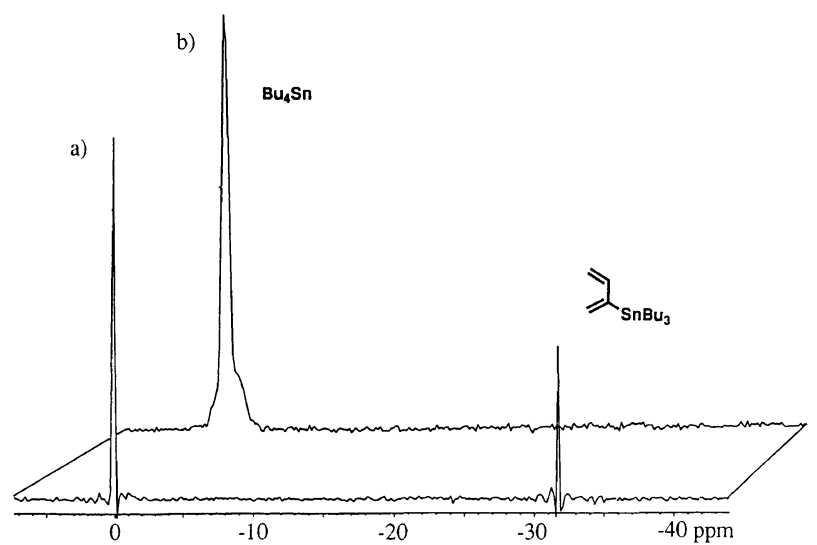

Figure 2. $149 \mathrm{MHz}{ }^{119} \mathrm{Sn} \mathrm{NMR}$ spectra of $\mathrm{Bu}_{4} \mathrm{Sn}$ and $\mathrm{BDSn}$ : a) mixture of $\mathrm{Bu}_{4} \mathrm{Sn}$ and $\mathrm{BDSn}$; b) reaction product of BDSn and $\mathrm{BuLi}$ after quenching with acetic acid.after $0.5 \mathrm{~h}$ at $-78^{\circ} \mathrm{C}$ with [BDSn] $=$ $[\mathrm{BuLi}]=0.5 \mathrm{~mol} \mathrm{~L}^{-1}$. tive formation of $\mathrm{Bu}_{4} \mathrm{Sn}$ with the consumption of $\mathrm{BDSn}$ in the reaction. These facts strongly support the quantitative conversion of BDSn to BDLi. The generation of the lithium species was completed in $30 \mathrm{~min}$ in THF even at $-78^{\circ} \mathrm{C}$ at a concentration of $0.5 \mathrm{~mol} \mathrm{~L}^{-1}$. Reactions using other solvents such as ether, toluene, and hexane were found to be unsuccessful. Phenyllithium can be used, but the separation of the formed phenyltributyltin is difficult.

\section{Tetrasiloxane Synthesis}

Frye ${ }^{13}$ reported that the reaction of $\mathrm{D}_{3}$ with 1.0 equivalent of BuLi in nonpolar solvent such as hexane and ether did not yield the trisiloxanolate, but $\mathrm{BuSiMe}_{2} \mathrm{OLi}$ was obtained along with unreacted $2 / 3 \mathrm{D}_{3}$. This suggests that the rate of the cleavage of acyclic siloxanolate is faster than that of ring-opening. However, we found that the reaction could be controlled by reaction conditions. The reaction of $\mathrm{D}_{3}$ with $\mathrm{BuLi}$ at $-78^{\circ} \mathrm{C}$ for $3 \mathrm{~h}$ in THF afforded the lithium trisiloxanolate, which remained unchanged even after $19 \mathrm{~h}$. In addition, the preference of the reaction was also dependent upon the species of organolithium reagent. In case of allyllithium, even the reaction in ether produced tetrasiloxanes after quenching with chlorosilanes in good yield. When an alkynyllithium or BDLi was used, the unsaturated function of the initially formed trisiloxanolate was not attacked by these otganolithium reagents even in THF. In these cases, ring-opening polymerization proceeded by the reaction of the initially formed lithium trisiloxanolate with excess $D_{3}$ at room temperature, suggesting that alkylative cleavage of the initially formed trisiloxanolate was not faster than the propagation reaction in these cases.

\section{Macromonomer Synthesis}

The products of ring-opening polymerization of $\mathrm{D}_{3}$ with 1-hexynyllithium were confirmed to have 1-hexynyl group at polymer end by ${ }^{1} \mathrm{H}$ NMR spectrum. The degree of polymerization was determined by integral ratio between methyl protons on silicon atom adjacent to 1hexynyl group $\left(\mathrm{Bu}-\mathrm{C}=\mathrm{C}-\mathrm{Si}\left(\mathrm{CH}_{3}\right)_{2}-\mathrm{O}-\right)$ and methyl protons on other silicon atoms of the polysiloxane segment. Macromonomers having $M_{n}$ ranging from $2000\left(M_{w}\right)$ $\left.M_{n}=1.3\right)$ to $12000\left(M_{w} / M_{n}=1.1\right)$ could be synthesized. However, the coincidence between feed $[\mathrm{M}] /[\mathrm{I}]$ and estimated degree of polymerization was not so good.

It is very important to quantitatively analyze the initiation and termination reactions to obtain well-defined macromonomers. It was confirmed by gas chromatographic analysis that, in the reaction between BDLi and $\mathrm{D}_{3}$ in $1: 1$ molar ratio at $0.5 \mathrm{moll}^{-1}, 1$-[2-(1,3-butadienyl)]nonamethyltetrasiloxane was quantitatively formed on complete consumption of butadiene as the initiator fragment in $3 \mathrm{~h}$ at $-78^{\circ} \mathrm{C}$ in THF after quenching with TMCS. When the reaction was carried out with $[\mathrm{M}] /$ $[\mathrm{I}]=2.0$, the amounts of $\mathrm{D}_{3}$ decreased to the half the initial amounts, and 1-[2-(1,3-butadienyl)nonamethyltetrasiloxane corresponding to the amounts of consumed $\mathrm{D}_{3}$ was detected. In the reaction with $[\mathrm{M}] /[\mathrm{I}]=10.0$ with $[\mathrm{I}]=0.5 \mathrm{moll}^{-1}$, butadiene was not detected at all after $3 \mathrm{~h}$ after quenching with acetic acid. Judging from these data, it was concluded that the initiator BDLi was 
quantitatively consumed in the initiation reaction in the actual polymerization system. Figure 3 shows the ${ }^{1} \mathrm{H}$ NMR spectrum of the products at $-78^{\circ} \mathrm{C}$ and at room temperature after quenching with TMCS.

The spectrum of Figure 3a was identical with that of the tetramer from the reaction of BDLi and $D_{3}$ in $1: 1$ molar ratio followed by quenching with TMCS. Polymer was formed at room temperature (Figure 3b). It was concluded that the initiation, namely, the ring-opening of $\mathrm{D}_{3}$ by $\mathrm{BDLi}$ occurred at $-78^{\circ} \mathrm{C}$. However, polymerization is very slow at this temperature. Higher reaction temperature was needed for the propagation reaction to proceed.

Ring-opening polymerization was carried out at several $\left[\mathrm{D}_{3}\right] /[\mathrm{BDLi}]$ ratios. The degree of polymerization can be estimated from the signal areas of total trimethylsiloxy groups and that of trimethylsiloxy groups adjacent to the dienyl function. The degree of polymerization increased with the ratio of monomer and the initiator (Table III). The addition of a second portion of monomer to the polymerization system increased molecular weight, maintaining relatively narrow molecular weight distribution. The addition of a second cyclic siloxane 1,3,5,-trimethyl-1,3,5,-trivinylcyclotrisiloxane yielded the block copolymer in good yield as evidenced by GPC analysis.

We sometimes had difficulty in GPC analysis of PDMS because of low sensitivity in RI and/or UV detection using THF as eluent, the most common solvent for many polymers. The introduction of UV-absorbing functional group at the end of the PDMS might improve the sensitivity to the detections to make the analysis more
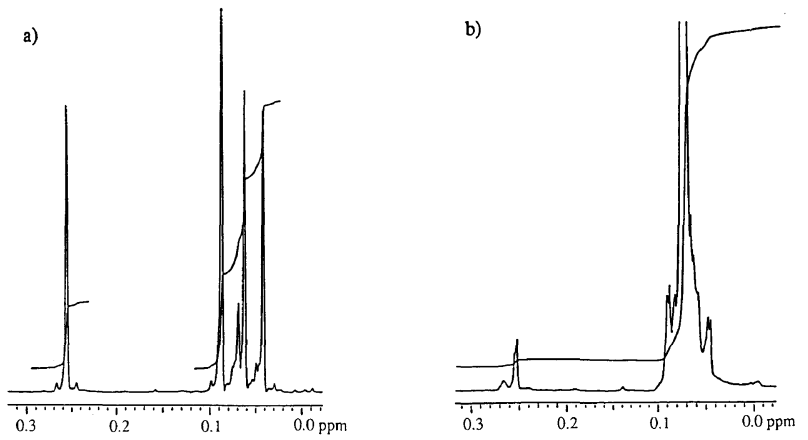

Figure 3. $300 \mathrm{MHz}^{1} \mathrm{H}$ NMR spectra of the reaction product of $\mathrm{BDLi}$ with $\mathrm{D}_{3}$ : a) at $-78^{\circ} \mathrm{C}$; b) at room temperature with $\left[\mathrm{D}_{3}\right]=0.8 \mathrm{~mol} \mathrm{~L}^{-1}$, $\left[\mathrm{D}_{3}\right] /[\mathrm{BDLi}]=10$. reliable. Several UV-absorbing functional groups were introduced at the end of PDMS by terminating the polymerization with chlorosilanes shown in Figure 1. Phenyldimethylchlorosilane and TMCS were used for comparison.

The results of the analysis of thus terminated PDMS in the ring-opening polymerization of $\mathrm{D}_{3}$ with $\mathrm{MeLi}$ as initiator, $\left[\mathrm{D}_{3}\right] /[\mathrm{MeLi}]=20$ by GPC are shown in Figure 4 and Table II.

The PDMS terminated by phenyldimethylchlorosilane exhibited relatively weak peaks in UV and RI compared with standard polystyrene in THF. PDMS terminated by TMCS did not show the corresponding peak in UV and rather weak peak in RI. Remarkable enhancement of sensitivity was observed when terminated by these UV-absorbing reagents. In case of cyanobiphenyl and pyrene terminated polymer, detection was made at 297 and $347 \mathrm{~nm}$, respectively, instead at commonly used $254 \mathrm{~nm}$. Coincidence of the observed and calculated molecular weights by using any of these terminating
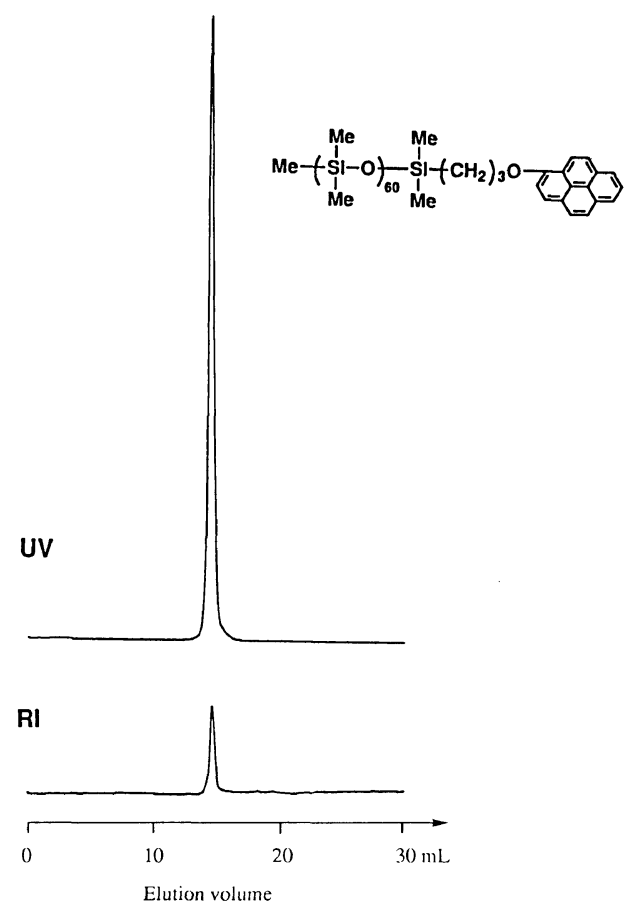

Figure 4. GPC chromatogram of PDMS terminated by 3-(1-pyrenyloxy)propyldimethylchlorosilane.

Table II. GPC analysis of PDMS terminated by UV-absorbing chlorosilanes ${ }^{\mathrm{a}, \mathrm{b}}$

\begin{tabular}{|c|c|c|c|c|c|}
\hline \multirow{2}{*}{$\mathbf{R}$} & \multicolumn{2}{|c|}{ Arbitrary peak height } & \multirow{2}{*}{$M_{n, \text { calcd }}$} & \multirow{2}{*}{$M_{n}^{\mathrm{f}}$} & \multirow{2}{*}{$M_{w} / M_{n}{ }^{\mathrm{f}}$} \\
\hline & $\mathrm{UV}\left(\times 10^{4}\right)^{\mathrm{c}}$ & $\mathrm{RI}\left(\times 10^{4}\right)$ & & & \\
\hline$-\mathrm{Me}$ & 0 & 0.4 & 4540 & $5150^{\mathrm{g}}$ & $1.13^{\mathrm{g}}$ \\
\hline-1 & 1.8 & 1.2 & 4600 & 4880 & 1.17 \\
\hline$+\left(\mathrm{CH}_{2}\right)_{3} \mathrm{O}-$ & 120 & 2.3 & 4770 & 5060 & 1.16 \\
\hline$\left.+\mathrm{CH}_{2}\right)_{3} \mathrm{O}-$ & $120^{\mathrm{d}}$ & & 4790 & 5080 & 1.13 \\
\hline$\left.+\mathrm{CH}_{2}\right)_{3} \mathrm{O}$ & $79^{e}$ & 1.3 & 4820 & 5140 & 1.13 \\
\hline
\end{tabular}

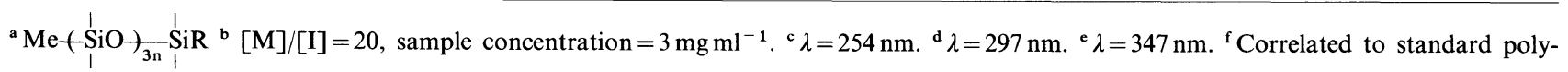
styrene. ${ }^{\mathrm{g}}$ Determined by RI. 
Table III. Molecular weight and molecular weight distribution of PDMS macromonomer with 1,3-butadienyl group

\begin{tabular}{|c|c|c|c|c|}
\hline \multirow{2}{*}{$\begin{array}{c}{[\mathrm{M}] /[\mathrm{I}]} \\
(\text { Feed) }\end{array}$} & \multicolumn{2}{|c|}{$M_{n}$} & \multirow{2}{*}{$M_{n, \mathrm{calcd}}$} & \multirow{2}{*}{$M_{w} / M_{n}^{\mathrm{c}}$} \\
\hline & ${ }^{1} \mathrm{H}$ NMR & $\mathrm{GPC}^{\mathrm{c}}$ & & \\
\hline $1^{\mathrm{a}}$ & 400 & - & 350 & - \\
\hline $5^{\mathrm{a}}$ & 1590 & - & 1240 & - \\
\hline $10^{b}$ & 2760 & 2610 & 2540 & 1.30 \\
\hline $20^{\mathrm{b}}$ & 5310 & 4810 & 4760 & 1.18 \\
\hline $30^{\mathrm{b}}$ & 7830 & 7440 & 6990 & 1.16 \\
\hline
\end{tabular}

${ }^{\mathrm{a}}$ Terminated by TMCS. ${ }^{\mathrm{b}}$ Terminated by [3-(biphenyl-4-yloxy)propyl]dimethylchlorosilane. ${ }^{\mathrm{c}}$ Correlated to standard polystyrene detected by UV at $297 \mathrm{~nm}$.

agents is quite good.

It should also be pointed out that enhancement of sensitivity was observed also in RI detection. Results of the synthesis of well-defined butadienyl functionalized PDMS macromonomers using [3-(biphenyl-4-yloxy)propyl]dimethylchlorosilane are summarized in Table III.

\section{CONCLUSION}

2-(1,3-Butadienyl)lithium was found to quantitatively initiate the polymerization of $\mathrm{D}_{3}$, confirmed by ${ }^{119} \mathrm{Sn}$ NMR and GC analyses. The ring-opening polymerization of $\mathrm{D}_{3}$ initiated with 2-(1,3-butadienyl)lithium and 1-hexynyl lithium proceeded in a living manner. Endcapping of the living PDMS by the chlorosilanes with
UV-absorbing functional group was effective for the precise determination of molecular weight and molecular weight distribution of PDMS by GPC.

Acknowledgments. The authors are grateful to ShinEtsu Chemicals Co., Ltd. for generous donation of organosilicon compounds. This work was supported in part by a Grant-in-Aid for Scientific Research ( 07555595 , 08455438) and a Grant-in-Aid for Scientific Research in Priority Areas, "New Polymers and Their NanoOrganized Systems" (08246223) from the Ministry of Education, Science, Sports, and Culture of Japan.

\section{REFERENCES}

1. A. L. Smith, Ed., "The Analytical Chemistry of Silicones," John Wiley \& Sons, New York, N.Y., (1991).

2. Y. Yamashita, Ed., "Chemistry and Industry of Macromonomers," Hutig \& Wepf, Basel, 1993.

3. Y. Kawakami, Y. Miki, T. Tsuda, R. A. N. Murthy, and Y. Yamashita, Polym. J., 14, 913 (1982).

4. A. Mori, T. Hishida, Y. Soga, and Y. Kawakami, Chem. Lett., 107 (1995).

5. A. Mori, H. Sato, K. Mizuno T. Hiyama, K. Shintani, and Y. Kawakami, Chem. Lett., 517 (1996).

6-9. L. A. Paquette, Ed., "Encyclopedia of Reagents for Organic Synthesis," John Wiley \& Sons, New York, 1995, Chapter 1, p 110, Chapter 5, 3001, Chapter 2, p 810 and p 812.

10. O. Tsuge, Bull. Chem. Soc. Jpn., 58, 1942 (1985).

11. Y. Kawakami and K. Toida, Macromolecules, 28, 816 (1995).

12. G. Chandra, P. Y. Lo, P. B. Hitchcock, and M. F. Lappert, Organometallics, 6, 191 (1987).

13. C. L. Frye, R. M. Salinger, F.W. G. Fearon, J. M. Klosowski, and T. DeYoung, J. Org. Chem., 35, 1308 (1970). 